\title{
PLAM - a meteorological pollution index for air quality and its applications in fog-haze forecasts in North China
}

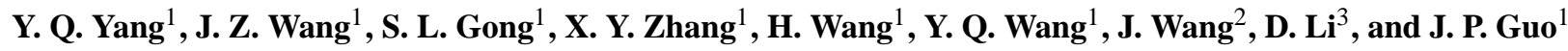 \\ ${ }^{1}$ Institute of Atmospheric Composition/Key Laboratory of Atmospheric Chemistry of China Meteorological Administration \\ (CMA), Chinese Academy of Meteorological Sciences (CAMS), Beijing, 100081, China \\ ${ }^{2}$ National Meteorological Information Center, CMA, Beijing, 100081, China \\ ${ }^{3}$ National Climate Center, CMA, Beijing, 100081, China \\ Correspondence to: S. L. Gong (sunling@camscma.cn) and J. Z. Wang (wjz@camscma.cn)
}

Received: 11 December 2014 - Published in Atmos. Chem. Phys. Discuss.: 25 March 2015

Revised: 5 January 2016 - Accepted: 6 January 2016 - Published: 8 February 2016

\begin{abstract}
Using surface meteorological observation and high-resolution emission data, this paper discusses the application of the PLAM/h index (Parameter Linking Air-quality to Meteorological conditions/haze) in the prediction of largescale low visibility and fog-haze events. Based on the twodimensional probability density function diagnosis model for emissions, the study extends the diagnosis and prediction of the meteorological pollution index PLAM to the regional visibility fog-haze intensity. The results show that combining the influence of regular meteorological conditions and emission factors together in the PLAM/h parameterization scheme is very effective in improving the diagnostic identification ability of the fog-haze weather in North China. The determination coefficients for four seasons (spring, summer, autumn, and winter) between PLAM/h and visibility observation are $0.76,0.80,0.96$, and 0.86 , respectively, and all of their significance levels exceed 0.001 , showing the ability of $\mathrm{PLAM} / \mathrm{h}$ to predict the seasonal changes and differences of fog-haze weather in the North China region. The high-value correlation zones are located in Jing-Jin-Ji (Beijing, Tianjin, Hebei), Bohai Bay rim, and southern Hebei-northern Henan, indicating that the PLAM/h index is related to the distribution of frequent heavy fog-haze weather in North China and the distribution of emission high-value zone. Through comparative analysis of the heavy fog-haze events and large-scale clear-weather processes in winter and summer, it is found that PLAM/h index $24 \mathrm{~h}$ forecast is highly correlated with the visibility observation. Therefore, the PLAM/h index has good capability in identification, analysis, and forecasting.
\end{abstract}

\section{Introduction}

Compared with the 1980s, fog-haze pollution events have increased significantly in the recent decade in the Beijing and North China region. Meteorological condition is one of the important elements that impacts the local aerosol accumulation and contributes to the frequent appearance of lowvisibility weather (Wang et al., 2002, 2010). Synthetic impact analysis of pollution-related atmospheric dynamics, thermodynamics, and chemical processes, as well as study of foghaze prediction, has drawn much attention. Long-term observations have pointed out that, in the last 30 years, foghaze phenomena in the central and eastern part of China have become more and more serious due to anthropogenic emissions. Under some meteorological conditions, aerosol particles in the atmosphere can be activated into cloud condensation nuclei $(\mathrm{CCN})$, which participate in the formation of clouds and fog, meaning that modern fog-haze has involved a great deal of polluted aerosol particles (e.g. $\mathrm{PM}_{2.5}$ ). To reduce the impact of fog-haze, as a strong weather disaster, special attention needs to be paid to atmospheric aerosol pollution (Zhang et al., 2013) Three-dimensional numerical modelling has improved to different degrees in meteorological services with regard to global air quality predictions (Gong et al., 2003; McKeen, 2007; Moran, 2009; Rigby et al., 2008; Zhang et al., 2009). Chemical forecasting model studies and prediction usually face the problem of timely emission data all over the world, therefore limiting the ability to achieve good forecasting accuracy. In recent years, through analysis of observational data of atmo- 
spheric aerosol particulate matter (PM) and the physical connection of sensitive meteorological parameters, air-qualityparameterized diagnostic prediction methods have been developed. Research results have revealed that the air quality meteorological index PLAM (Parameter linking Air-quality to Meteorological conditions) achieved reasonable results when it was applied in the prediction of air quality in Beijing during the 2008 Beijing Olympic Games. Identification and prediction studies using the meteorological conditions PLAM index for air quality have been made in China and abroad in recent years (Zhang et al., 2009; Honoré et al., 2008; Li et al., 2010; Kassomenos et al., 2008; Yang et al., 2009; Wang et al., 2013). Studies have indicated that the contribution of the meteorological conditions PLAM index from emissions is of great importance as emissions (Zhang et al., 2009; Wang et al., 2012) have marked impacts on the regional distribution of air quality in different areas. However, there have been very few studies on emission contribution to the air quality meteorological index, including its quantitative expression, physical mechanism, and diagnostic prediction. This is especially critical in establishing the relations and mechanism of large-scale high-value $\mathrm{PM}_{2.5}$ and low-visibility weather.

On the basis of the parameterized meteorological condition principle method, this paper discusses the mutual impact of emissions and meteorological conditions, in addition to studying the structure and function of the meteorological conditions PLAM index in quantitatively identifying, diagnosing, and forecasting large areas of fog-haze weather.

\section{Data and methods}

This paper uses near-real-time (NRT) operational data, including surface observation data, from which the elements related to the impact of meteorological conditions are extracted, such as atmospheric temperature, difference of temperature and dew point, clouds, weather phenomena, air pressure, wind direction and speed and visibility, and high-level sounding data, as well as data from atmospheric component observing system stations. Multi-source element data including high-resolution emission data were analysed to investigate the meteorological conditions PLAM index identification method for forecasting wide-range low visibility and fog-haze.

\subsection{Analysis of wet-equivalent potential temperature, $\theta_{\mathrm{e}}$, features of uniform air mass}

Air quality and meteorological condition impacts are closely related. Usually, different air mass structures can lead to significant differences in meteorological conditions. Studies have pointed out that, aiming at the impact on air quality, it is very important to analyse and distinguish what kind of air mass controls and affects the local area; identify the differences in atmospheric aerosol features for different types of air masses, including maritime, continental, or polar air masses; and consider the identification of stagnant air masses. The property of wet-equivalent potential temperature, $\theta_{\mathrm{e}}$, can be used to distinguish the types of air masses, because $\theta_{\mathrm{e}}$ includes dry and wet adiabatic processes, lifting condensation, and sinking, as well as other dynamic and thermodynamic processes in the atmosphere. The equation for wet-equivalent potential temperature is

$\theta_{\mathrm{e}}=\theta \exp \left[\left(\frac{L w}{C_{\mathrm{p}} T}\right)\right]$,

where $\theta$ is potential temperature,

$\theta=T\left[\left(\frac{1000}{P}\right)^{\frac{R_{\mathrm{d}}}{C_{\mathrm{p}}}}\right]$.

$\theta$ and $\theta_{\mathrm{e}}$ are in units of kelvin. $w, C C_{\mathrm{p}}, L, R_{\mathrm{d}}, P$, and $T$ represent mixing ratio, constant-pressure specific heat $\left(C_{\mathrm{p}}=1.005 \mathrm{~J} \mathrm{~g}^{-1}{ }^{\circ} \mathrm{C}^{-1}\right)$, latent heat of condensation of water vapour $\left(L=2500.6 \mathrm{~J} \mathrm{~g}^{-1}\right)$, gas constant $\left(R_{\mathrm{d}}=2.87 \times 10^{-1} \mathrm{~J} \mathrm{~g}^{-1}\right.$ degree $\left.^{-1}\right)$, air pressure, and temperature, respectively.

\subsection{Parameterized method for diagnosing and forecasting atmospheric process}

The interactions and mutual effects of atmospheric microphysical process and large-scale process, as well as the different scales of process, are very complicated in the the transition processes between haze and fog as well as atmospheric pollution process. The principle and main idea of the parameterized method is to connect the non-linear relationship that is difficult to describe in the processes of different scales with a parameterization scheme. Studies by Kuo (1961, 1965, 1974) have shown that the micro-processes in cloud physics can be described in a parameterization scheme with largescale observations. Based on the Lagrangian method, the variation in fluid particle group with time can be followed, i.e. identifying the "stagnant and less changing" state of air masses. In atmospheric particle movement, the individual change in wet-equivalent potential temperature (spatialtemporal total derivative) becomes a small value or zero, meaning little change. Therefore, according to the identification of the "stagnant and less changing" property of wetequivalent potential temperature of air masses, i.e. the basic physical process of $\mathrm{d} \theta_{\mathrm{e}} / \mathrm{d} t \approx 0$, the possible varying trend of air quality of the "stagnant and less changing" air masses can be diagnosed and predicted. The recently developed air quality diagnosis of the parameterized meteorological conditions (Yang et al., 2009; Zhang et al., 2009; Wang et al., 2012) PLAM index is described as follows: 
$\operatorname{PLAM}_{0}=\mathrm{d} \theta_{\mathrm{e}} / \mathrm{d} t \approx \theta_{\mathrm{e}} \frac{f_{\mathrm{c}}}{C_{\mathrm{p}} T}$

$\theta_{\mathrm{e}}$ is the wet-equivalent potential temperature given by Eq. (1). $f_{\mathrm{c}}$ is the wet air condensation rate:

$f_{\mathrm{c}}=f_{\mathrm{cd}} /\left[\left(1+\frac{L}{C_{\mathrm{p}}} \frac{\partial q_{\mathrm{s}}}{\partial T}\right)_{p}\right]$.

$f_{\text {cd }}$ is dry air condensation rate:

$f_{\mathrm{cd}}=\left[\left(\frac{\partial q_{\mathrm{s}}}{\partial P}\right)_{T}+\gamma_{p}\left(\frac{\partial q_{\mathrm{s}}}{\partial T}\right)_{p}\right]$

$\gamma_{p}$ is dry-adiabatic lapse rate:

$\gamma_{p}=\frac{R_{\mathrm{d}}}{C_{\mathrm{p}}} \cdot \frac{T}{P}$

Finally, $q_{\mathrm{s}}$ is specific humidity. All other variables are the same as mentioned above.

Equation (3) shows that the parameterized method based on the spatial-temporal variation in wet-equivalent potential temperature of air masses has practical application prospects in analysing, diagnosing, and forecasting the changes in air quality. The objective of this paper is to further discuss the impact and identification of the PLAM ${ }_{0}$ index with regard to aerosol pollution concentration accumulative increase and atmospheric fog-haze weather and, moreover, to study the possibility of using the parameterized method to improve the diagnosing and forecasting capability regarding large-scale disastrous fog-haze weather.

\subsection{Contribution and impact of atmospheric emission on PLAM index}

Considering the diagnosis and forecasting analysis of atmospheric fog-haze, which is closely related to atmospheric aerosols (such as fine particles, $\mathrm{PM}_{2.5}$ ), it is very important to integrate the meteorologically based parameter PLAM $_{0}$ with the emission contributions. In order to integrate the initial meteorological conditions related to atmospheric pressure, temperature, humidity, condensation, etc. with the contribution of the pollutant emission factor, $p$, in the atmosphere, the identification parameter is expressed by Eq. (7) (Wang et al., 2012):

PLAM_haze $=\operatorname{PLAM}_{0} \times p$.

This factor $p$ further expands the application of the PLAM index and investigates the description of the function and impact of the index by emissions in the forming and developing process of regional wide-range fog-haze events, namely PLAM_haze (abbreviated as PLAM/h). Thus, analysis of the latest emission research results as of 2010 is introduced, including industry, energy source, transportation, and anthropogenic emission source combined $E_{\mathrm{PM}_{2.5}}$ (unit: tonnes $\times 10$ ) (Fig. 1a). It is seen from Fig. 1a that the highvalue zones from industry, energy source, transportation, and anthropogenic emission source in the North China region involve (1) the central and southern part of Hebei (including Beijing and Tianjin), (2) the central and western part of Shandong, (3) the central part of Henan, (4) the eastern part of Hubei, (5) the Yangtze River delta, and (6) the eastern part of Sichuan (the Chengdu Plain). All of these high-value emission sources have significant impacts on the fog-haze weather in North China and cannot be ignored.

To quantify the impact of emission in PLAM index, the probability of its impact on the surrounding area satisfies the normal distribution - that is, by separating the impacts of meteorological condition and emission on the surrounding part, it is always isotropic and the impact probability of the high-emission centre area is higher than that of the surrounding area. As a result, the emission impact satisfies the form of two-dimensional probability distribution, and the integral probability density function that falls into the surrounding limited-area $x-y$ plane $(s)$ is as follows (Wang and Neumann, 1985; Neumann and Mandal, 1978):

$P^{\prime}(s)=\iint_{s} f(x, y) \mathrm{d} x \mathrm{~d} y=1-\exp \left(-\gamma^{2} / 2\right)$,

where $\gamma$ is the standardized (normalized) grade of the emission source intensity in the forecasting area concerned, $\gamma \in(0,1)$, defined as $\left.\gamma=\left(E-E_{\min }\right) / E_{\max }-E_{\min }\right)$, where $E_{\max }$ and $E_{\min }$ are the maximum value and minimum value of the emission $E$ in the specified season of the studied impact region (North China). In other words, the exponential growth rate with emission impact is $P=1+P^{\prime}$. Then, the impact of emissions on the increased value of fog-haze is taken into account, and the Eq. (3) can be formulated into

$\mathrm{PLAM} / \mathrm{h}=\theta_{\mathrm{e}} \frac{f_{\mathrm{c}}}{C_{\mathrm{p}} T} \times p(\gamma)$.

\section{Results and discussion}

\subsection{Analysis of PLAM index medium emission contribution features}

Studies have pointed out that emission does not change much in certain fixed temporal scales (such as a month or a season) in the same area but that it differs greatly in different places. To analyse the contribution of regional emission to low-visibility weather such as fog-haze, the comparable standardized emission intensity $(\gamma)$ in the regional and seasonal period was calculated based on the meteorological observation data in different places and during different time periods. Figure 1a presents the distribution of high-resolution emission lists. Figure $1 \mathrm{~b}$ is the standardized distribution of emission lists in the North China region based on Fig. 1a. From 

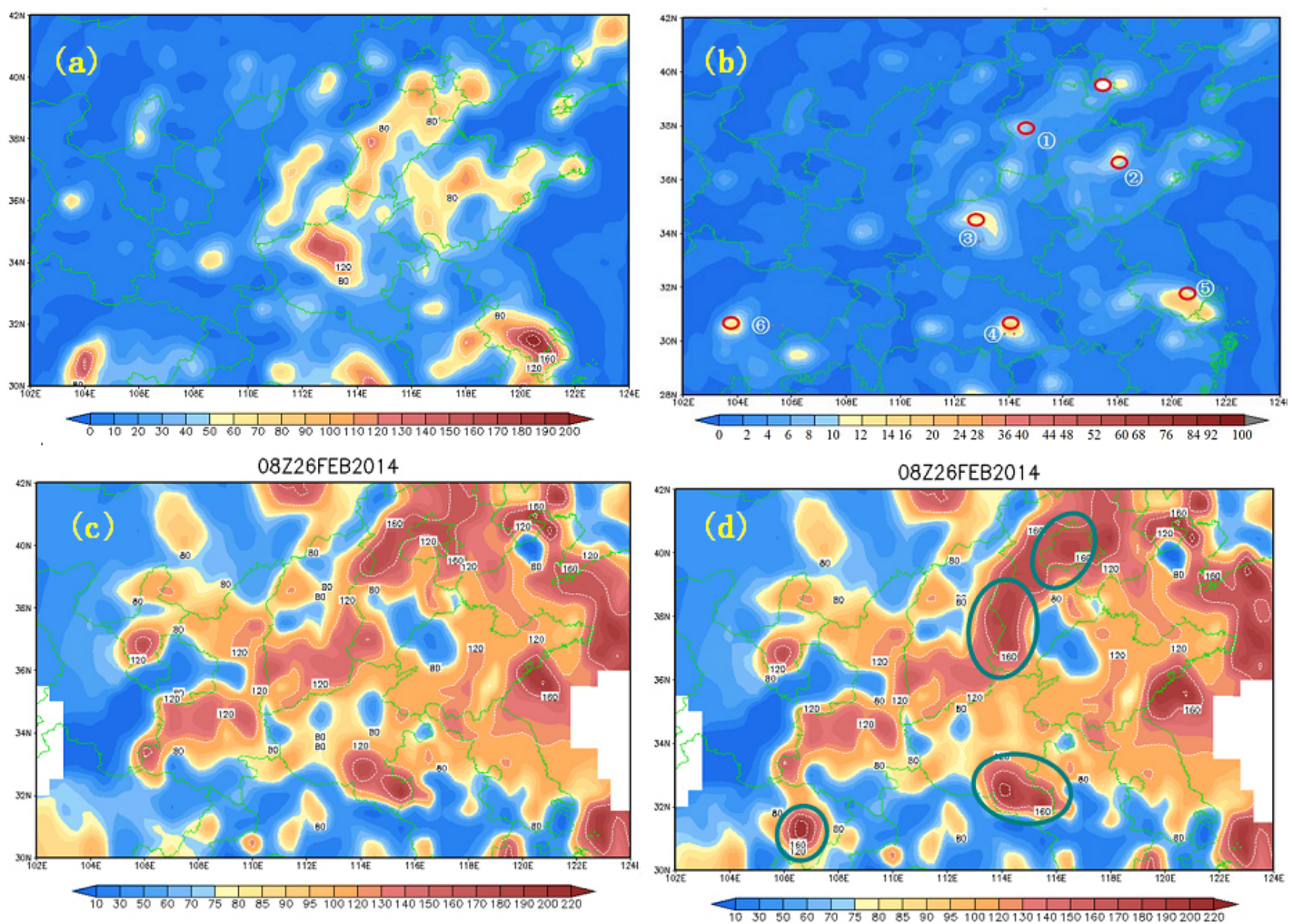

Figure 1. High-resolution emission list $E$ distribution (a) and its regional emission standardized list $\gamma$ (b). PLAM index distribution ignoring (c) and considering (d) the emission conditions in North China at 08:00 (UTC+8) on 26 February 2014.

Fig. 1b, it can be seen that (1) Beijing, Tianjin, and the central and southern part of Hebei; (2) the west of Shandong; (3) the central part of Henan; (4) the eastern part of Hubei; (5) the Yangtze river delta; and (6) the east of Sichuan remain as areas of significantly concentrated high emission, whose circular or oval-shaped distribution characteristics are clearly seen. Taking the rarely seen large-scale heavy foghaze weather event over Beijing and the North China region on 26 February 2014 as an example, the difference between considering and ignoring the emission contribution in the PLAM index is discussed. Figure 1c and d show the PLAM index distribution under the conditions of considering and ignoring the emission in North China at 08:00 $($ UTC +8$)$ on 26 February 2014. It is seen from the figure that, without considering the emission impact (Fig. 1c), the distribution centres of the PLAM index are Hebei, Beijing, Tianjin and part of the Hubei, Henan and Sichuan provinces. The PLAM indices are 120, 160, 160, and 80 (Fig. 1c), respectively. Figure $1 \mathrm{~d}$ shows PLAM/h distribution with the emission impact. The above-mentioned four PLAM/h index high-value zones have values of $180,180,180$, and 160 , respectively. The PLAM/h value increases along with the significant expansion of high values (the green ovals in Fig. 1d).

To further discuss the difference, Fig. 2 displays the correlation analysis of $24 \mathrm{~h}$ forecasting and visibility of the PLAM/h index at 673 stations in North China on 26 February 2014. For ease of comparison, the correlation distributions of PLAM/h and visibility under the conditions of including and excluding emission factors are superimposed. The considered emission in Fig. 2 is shown as blue triangles, while the ignored emission is marked with yellow circles. The respective correlation fitted lines are marked by a red solid line and yellow dashed line. It is seen from Fig. 2 that reasonable correlation exists between PLAM/h and visibility on 26 February 2014, regardless of emission contributions. However, the determination coefficient $\left(R^{2}\right)$ is increased from 0.3675 to 0.3887 when emissions are considered, indicating the importance of inclusion of emission in $\mathrm{PLAM} / \mathrm{h}$. 


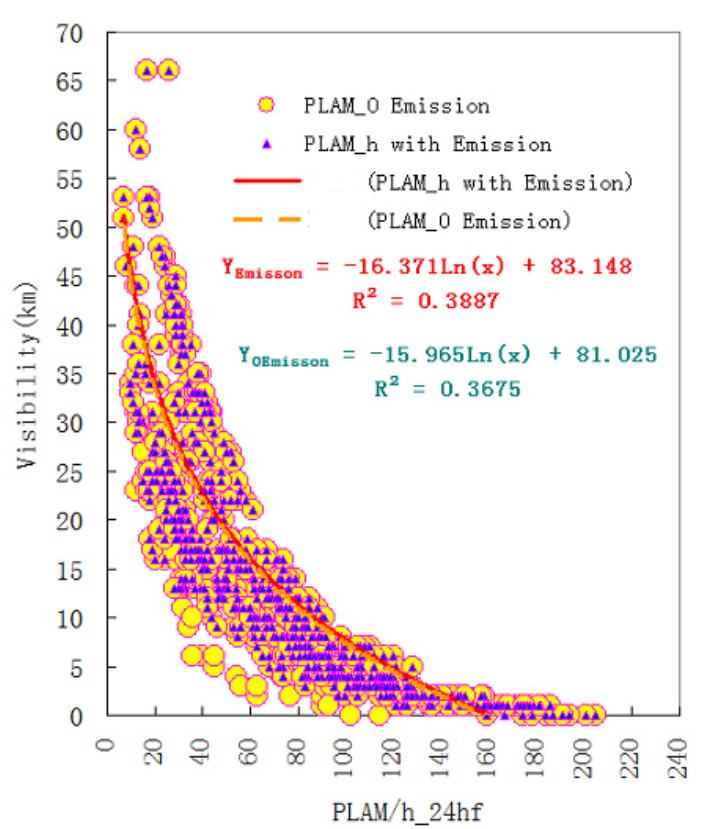

Figure 2. Correlation analysis of PLAM and visibility considering and excluding emission factors on 26 February 2014.

It is noted that, in the low-value visibility range (Vis $<10 \mathrm{~km}$ ), the PLAM/h index value without emission impact clearly shifts towards the low-value zone. Comparatively, the closer to the high-value zone of visibility, the more the two types of symbols tend to overlap, which suggests that, without emissions, the predictive value of the PLAM/h index will be smaller and its correlation with visibility will be reduced, deviating from the fitted low-value zone line.

In summary, the above analyses on the regional PLAM $/ \mathrm{h}$ distribution (Fig. 1) and the correlation distribution of PLAM/h and visibility (Fig. 2) all indicate that, with the combined impact of meteorological condition and emission factors, the description capability of the PLAM/h index increases significantly with the index value expanding to the high-value zone; the PLAM/h index including the emission has an obvious impact on improving the capability of diagnosing and identifying heavy fog-haze weather.

\subsection{Analysis of seasonal characteristics of PLAM/h index and visibility correlation}

Figure 3 separately presents distributions of fog-haze weather in the typical heavy fog-haze process cases in four seasons, including the PLAM/h (a) and visibility (b) of the 14 April 2011 spring case, the PLAM/h (c) and visibility (d) of the 26 July 2008 summer case, the PLAM/h (e) and visibility (f) of the 30 October 2011 autumn case, and the PLAM/h (g) and visibility (h) of the 7 January 2011 winter case.

In spring, the PLAM/h index low-value zone on 14 April 2011 is mainly in the North China region. Three- quarters of regional PLAM/h values are $<70$ in the whole region. The meteorological condition is good for pollutants to diffuse. There is a PLAM/h relatively high-value zone across central Henan, southern Hebei, Beijing-Tianjin, and northern Hebei, which is PLAM/h $\geq 80$. Moreover, there is another high-value zone in the coastal parts of the Bohai Sea, corresponding to the sea-fog-prone area in the southern part of North China. The high PLAM/h value matches with the low-value zone of visibility, whilst the large-scale PLAM/h low-value zone fits with the high-value zone of visibility.

In summer, the 08:00 (UTC+8) 26 August 2008 case shows that the North China region is a large-scale PLAM/h high-value zone, whose centre is distributed in a north-south banding shape: (1) east of the Taihang Mountains in Henan province to southern Hebei (where the PLAM/h value is 120 and the highest even reaches 200), (2) Beijing and central Hebei (where the PLAM/h value is $120-140$ ), (3) the Jing-Jin-Tang (Beijing, Tianjin, Tangshan) region (where the $\mathrm{PLAM} / \mathrm{h}$ value is high, up to $120-240$ ), and (4) southwest Shandong (where the PLAM/h value reaches 140-200) are four remarkable banding high-value centres. Corresponding to the wide-range, low-visibility, low-value zones, the visibility in most parts is lower than $10 \mathrm{~km}$, of which the visibility from Henan to southern Hebei is lower than $4 \mathrm{~km}$. The Beijing-Tianjin region has a visibility of only $4-8 \mathrm{~km}$. Therefore, the PLAM/h index has a significant effect on diagnosing and identifying the summer fog-haze weather in North China.

North China usually has clear and comfortable autumn weather. But in recent years, heavy fog-haze weather events have appeared more and more frequently in autumn. To examine the identifying capability of the PLAM/h index in the typical autumn heavy fog-haze case, we analyse the rarely seen heavy fog-haze pollution process that happened in North China on 30 October 2011. According to Fig. 3g and $\mathrm{h}$, the high-value PLAM/h index in the fog-haze area in North China assumes a north-south trend parallel to the regional distribution of three large-scale bands (Fig. 3e) and $\mathrm{PLAM} / \mathrm{h}>200-240$, of which the three high-value PLAM/h bands are parallel to the Taihang Mountains in North China and orderly arranged along the line of the boundary between Shanxi and Hebei-southern Liaoning (dotted line in the figure) and greatly consistent with the banding distribution of the fog-haze and low-visibility areas in North China (Fig. 3f). The large range of PLAM/h low-value zone, PLAM $<20$ 50 , in the western and northern parts of North China agrees with the high-value visibility zone with Vis $>20 \mathrm{~km}$. Therefore, PLAM index has the characteristics of weather-scale banding distribution similar to the distribution of weather systems.

One heavy fog-haze process rarely seen in history appeared in North China in the first half of January 2013. This is a typical winter heavy fog-haze case, whose PLAM/h index is significantly high, indicating the contribution of meteorological conditions to the enhancement and persistence of 

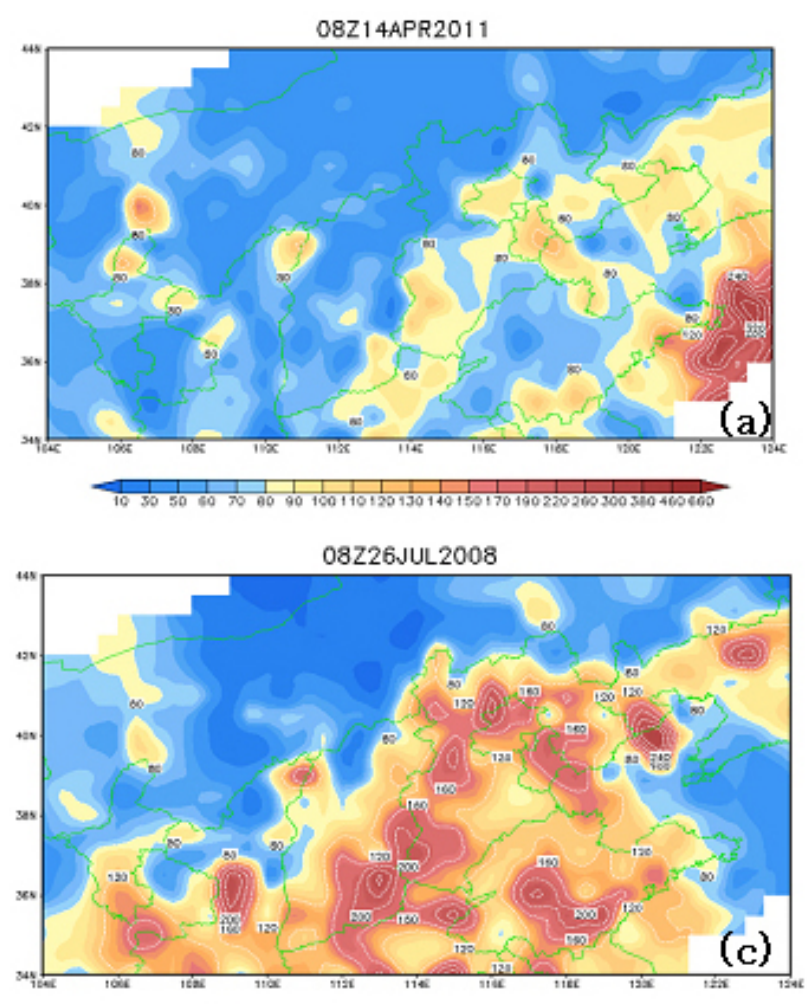

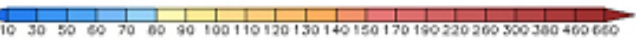



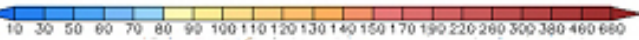

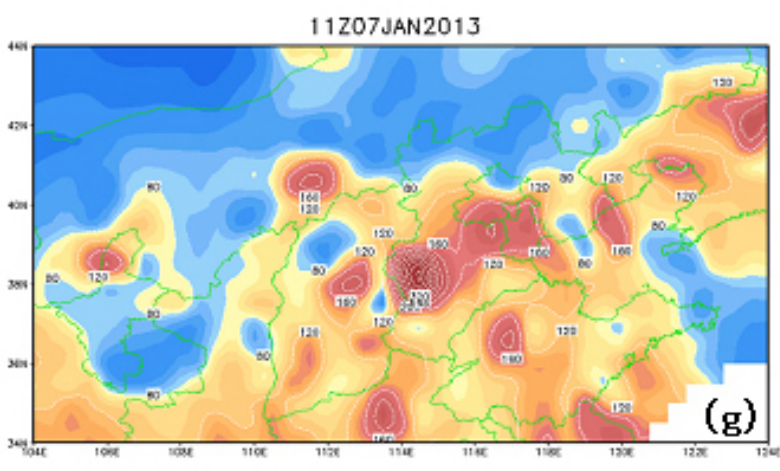

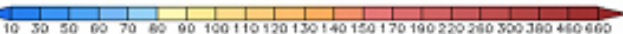
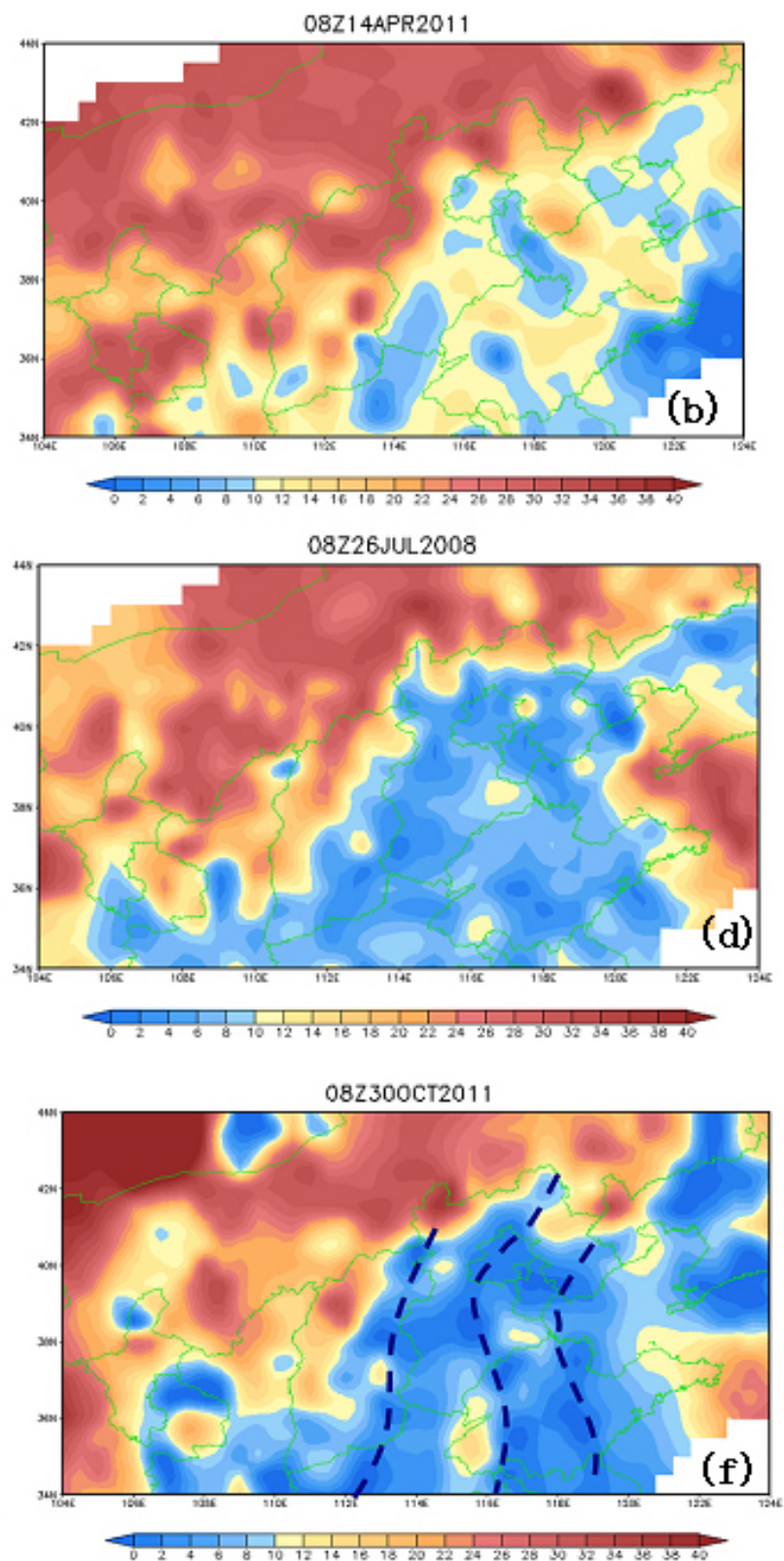

11Z07JAN2013

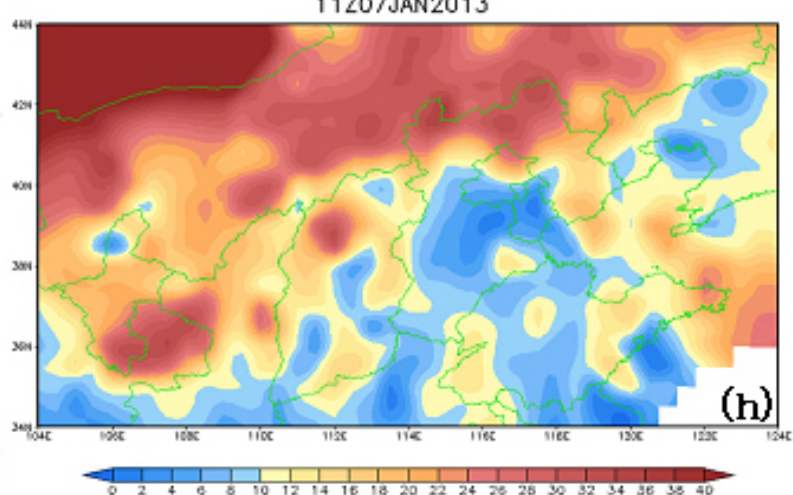

Figure 3. Cases for PLAM/h (a) and visibility (b) on 14 April 2011, PLAM/h (c) and visibility (d) on 26 July 2008, PLAM/h (e) and visibility (f) on 30 October 2011, and PLAM/h (g) and visibility (h) on 7 January 2011. 

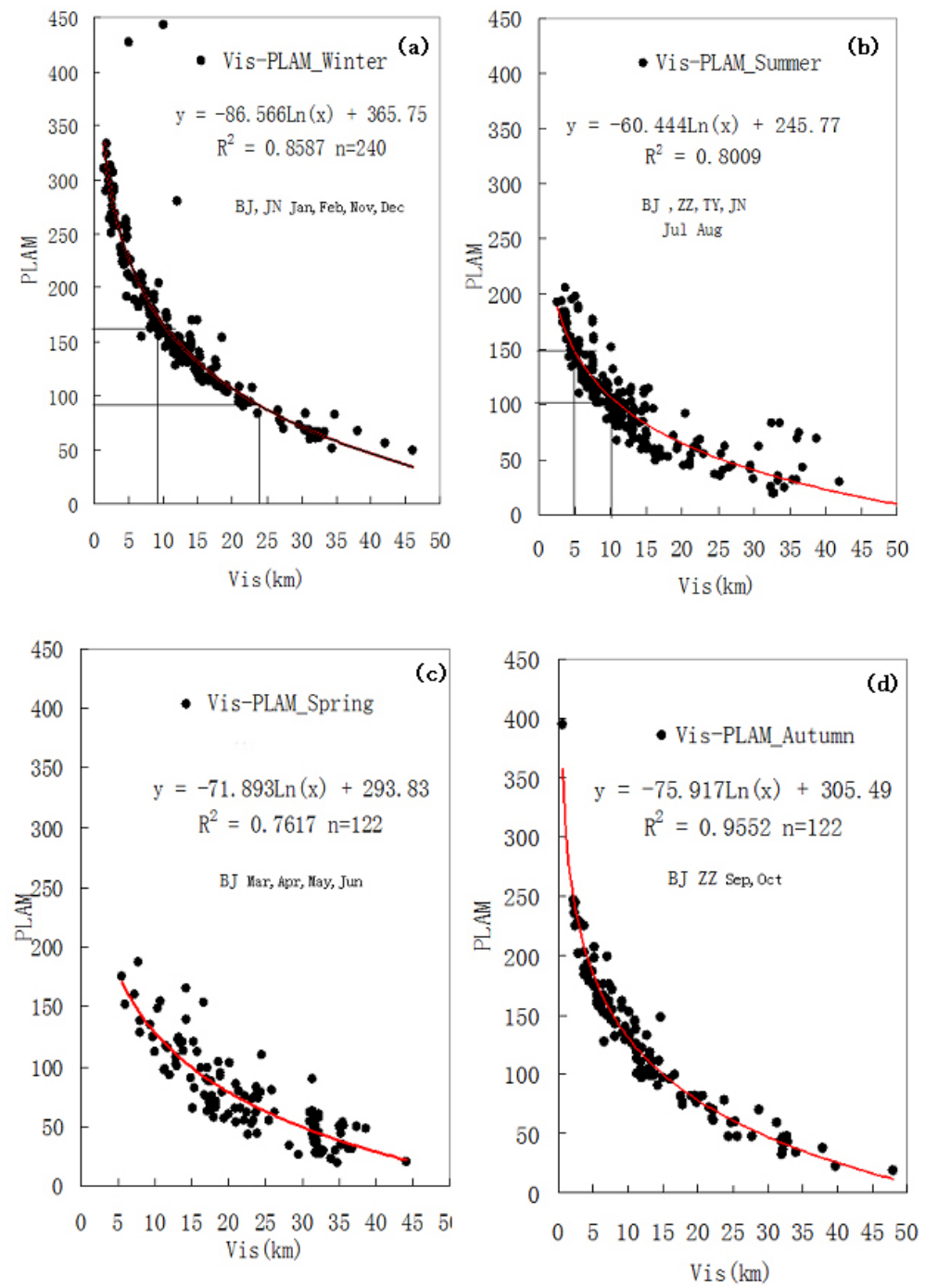

Figure 4. Correlation analysis of PLAM/h index and visibility in winter (a), summer (b), spring (c), and autumn (d).

this large-scale fog-haze process. The PLAM/h index highvalue zone blankets the Beijing-Tianjin region, the east side of the Taihang Mountains and the south side of the Yanshan Mountains. The banding fog-haze weather area in the southwest-northeast trend extends eastward into the southern part of Liaoning. Corresponding to the southwest-northeast trend banding high-value zone of PLAM/h index (Fig. 3g), the visibility is the corresponding banding low-value distribution area (Fig. 3h).

The seasonal results analysis of the PLAM/h index shows its characteristic linkage with weather-scale system in each season. The weather-scale high-value PLAM/h zone agrees with the low-value visibility area, which indicates that the regional distribution of the PLAM/h index is useful in diagnosing, identifying, and forecasting the large-scale fog-haze area in four seasons in North China.
Figure 4 reveals the correlation of the PLAM/h index and visibility in different seasons, which is calculated by Eq. (9) according to the 2009 daily observation data in Beijing. As the seasonal features related to aerosol pollution in North China are different from the seasonal features divided according to temperature elements, the selected representative stations are slightly different. For the analysis of this paper, in North China, the season from July to August is defined as the rainy season or summer, and from November to the following February is defined as winter. Spring and autumn are two transition seasons, spanning March to June and September to October, respectively. In Fig. 4a the chosen period of winter includes January-February and NovemberDecember of Beijing (BJ) and Zhengzhou (ZZ); in total, there are 240 groups of observation records. In Fig. $4 \mathrm{~b}$ there are in total 248 groups of observation records chosen for the summer (July-August) of Beijing (BJ), Zhengzhou (ZZ), 




Figure 5. Regional correlation between PLAM/h index and visibility obtained from the 1006 groups of observation samples collected from January 2009 to December 2012. The regional distribution of the correlation with significance level exceeding 0.001 is shown.

Taiyuan (TY), and Jinan (JN). Figure 4c involves 122 groups of records from Beijing (BJ) for the season of spring (MarchJune). Figure 4d contains 122 groups of observation records for the autumn (September-October) of Beijing (BJ) and Zhengzhou (ZZ). The following can be seen from the figures:

1. The variation in air quality meteorological conditions $\mathrm{PLAM} / \mathrm{h}$ index is significantly correlated with the visibility observation (Vis) in Beijing and the determination coefficients $\left(R^{2}\right)$ are 0.8587 (winter), 0.8009 (summer), 0.7617 (spring), and 0.9552 (autumn), respectively, with all significance levels exceeding 0.001 .

2. In winter (Fig. 4a), with the low-value meteorological conditions index, when PLAM/h $<80$, Vis $>25 \mathrm{~km}$; when the high value of PLAM/h reaches 150-350, the observed visibility trend worsens, with Vis $<10 \mathrm{~km}$. Different from winter, during the low-value meteorological condition index in summer, when PLAM $<150$, Vis $>10 \mathrm{~km}$; when the PLAM high value rises to 150 , the observed visibility becomes worse and Vis $<5 \mathrm{~km}$ (Fig. 4b). This means that PLAM/h has significant capability in describing optimal or inferior visibility and, moreover, its seasonal difference is great. This finding is consistent with the climate observation result that the aerosol concentration high value in summer appears at the same rate as with low visibility (Wang and Liu, 2006).

3. Figure 4 shows that the correlations in the two transition seasons are noticeably different. The correlation features in spring are similar to those in summer, while the autumn features are like those of winter. But during the transition seasons, spring and autumn, the threshold value deduced from the diagnosis of PLAM/h to heavy fog-haze pollution is lower - that is, when the meteorological condition index PLAM/h reaches 150 , visibility is very low, even Vis $<1 \mathrm{~km}$.

In summary, the above analyses indicate that PLAM/h is capable of describing the changes in visibility, and also very well capable of distinguishing the seasonal differences.

\subsection{PLAM index and related features of visibility area}

Figure 5 shows the regional correlation between PLAM/h index and visibility which is obtained from the 1006 groups of observation samples collected from January 2009 to December 2012. The regional distribution of the correlation with significance level exceeding 0.001 is also shown. The figure indicates that most of North China is a high-value zone $>80 \%$; one high-value zone is located in Shanxi, most of southern Hebei, and northern Hubei, which is likely related to the favourable meteorological conditions of lowlevel southerly airflow which is to the east of the Taihang Mountains in North China, as well as to the distribution of high-emission areas in southern Hebei and northern Hubei (Fig. 1b). Another highly correlated zone located in BeijingTianjin and the Bohai Bay is possibly related to the weather conditions of the fog-haze "back-flow" of the easterly wind in North China. These analyses suggest that the North China $\mathrm{PLAM} / \mathrm{h}$ and index features are significantly correlated with visibility; the high-correlation area with significance level 

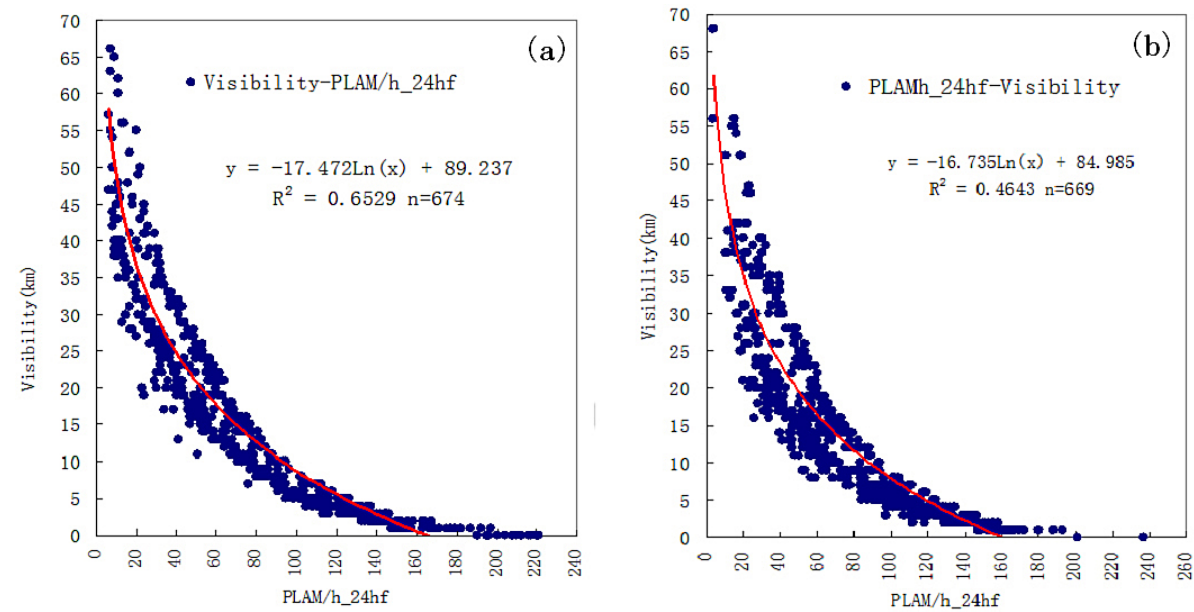

Figure 6. Correlation analysis results of PLAM/h index $24 \mathrm{~h}$ forecasts and observed visibility at 08:00 (UTC+8) on 20 February 2014 (a) and 08:00 (UTC+8) on 22 February 2014 (b).

exceeding 0.001 is likely related to the regional distribution of meteorological condition of heavy fog weather in North China and the distribution of regional emission high-value zones in North China.

\subsection{Application of PLAM/h index in fog-haze forecasting}

\subsubsection{The 20-26 February 2014 winter case analysis}

Through application of the PLAM/h index developed in this paper, $24 \mathrm{~h}$ forecasts of visibility with PLAM/h are conducted for one historically rarely seen winter heavy fog-haze process in North China during the last half of February 2014 (20-26 February 2014). During the test, the NRT data of more than 670 stations in the North China region are adopted to analyse the correlation between PLAM/h index $24 \mathrm{~h}$ forecasts and visibility observation. Figure $6 \mathrm{a}$ and $\mathrm{b}$ show the correlation analysis results of PLAM/h index $24 \mathrm{~h}$ forecasts and observed visibility, respectively, at 08:00 (UTC+8) on 20 February 2014 and 08:00 (UTC+8) on 22 February 2014. Table 1 lists the correlation of daily PLAM/h index $24 \mathrm{~h}$ forecasts and visibility during the whole period of the regional heavy fog-haze event over North China during 20-26 February 2014, as well as the number of stations that are involved in the test.

From Fig. 6 and Table 1 it can be seen the daily determination coefficients $\left(R^{2}\right)$ are $0.6529,0.5424,0.6047,0.6040$, 0.4550 , and 0.3887 , respectively; the significance levels all exceed 0.001 , which means their correlation is very good.

\subsubsection{The 19-22 July 2013 summer case analysis}

To further investigate the forecasting capability of the summer PLAM/h index with regard to the fog-haze area distribution, forecast application and analysis testing of one heavy
Table 1. Correlation of daily PLAM/h index $24 \mathrm{~h}$ forecasts and visibility during the whole period of the regional heavy fog-haze event over North China during 20-26 February 2014.

\begin{tabular}{lcc}
\hline Forecast time & $\begin{array}{c}\text { Determination } \\
\text { coefficient } \\
\left(R^{2}\right)\end{array}$ & $\begin{array}{c}\text { No. of } \\
\text { station }\end{array}$ \\
\hline 08:00 (UTC+8), 20 Feb & 0.6529 & 674 \\
08:00 (UTC+8), 21 Feb & 0.5424 & 668 \\
08:00 (UTC+8), 22 Feb & 0.4634 & 669 \\
08:00 (UTC+8), 23 Feb & 0.6047 & 676 \\
08:00 (UTC+8), 24 Feb & 0.6040 & 673 \\
08:00 (UTC+8), 25 Feb & 0.4550 & 678 \\
08:00 (UTC+8), 26 Feb & 0.3887 & 673 \\
\hline
\end{tabular}

fog-haze pollution process in North China in summer, 1922 July, 2013 are carried out. On 19 July, extremely heavy fog emerged in the evening over Beijing, with local visibility less than $5 \mathrm{~m}$. Figure $7 \mathrm{a}$ and $\mathrm{b}$ show the correlation analysis result of PLAM/h index $24 \mathrm{~h}$ forecast and visibility, respectively, during the polluting process in the North China region at 08:00 (UTC +8$)$ on 20 and 22 July 2013. Table 2 presents the correlation of daily PLAM/h index $24 \mathrm{~h}$ forecast and visibility during the whole process of the regional heavy foghaze event over North China during 19-22 July 2013, as well as the number of stations that are part of the forecasting test. From Fig. 7 and Table 2, the daily (19-22 July) determination coefficients $\left(R^{2}\right)$ are respectively $0.4988,0.4826,0.5416$, and 0.5263 , and all their significance levels exceed 0.001 .

The above analyses indicate that the PLAM/h index $24 \mathrm{~h}$ forecasts and visibility observations of the large-scale samples in different winter and summer periods over North China all have higher correlations. This result illustrates that the PLAM/h index would have good practical applica- 



Figure 7. Correlation analysis of the regional PLAM/h index $24 \mathrm{~h}$ forecasts and visibility during the whole period of pollution in North China at 08:00 (UTC+8) on 20 July 2014 (a) and 08:00 (UTC+8) on 22 July 2014 (b).


Figure 8. Distribution of PLAM/h in North China (a) and correlation analysis of PLAM/h index 24 h forecasts and observed visibility (b) in North China for 08:00 (UTC+8) on 12 March 2014 .

Table 2. Correlation of daily PLAM/h index $24 \mathrm{~h}$ forecasts and visibility during the whole period of the regional heavy fog-haze event over North China during 19-22 July 2013.

\begin{tabular}{lcc}
\hline Forecast time & $\begin{array}{c}\text { Determination } \\
\text { coefficient } \\
\left(R^{2}\right)\end{array}$ & $\begin{array}{c}\text { No. of } \\
\text { stations }\end{array}$ \\
\hline 08:00 (UTC+8), 19 Jul & 0.4988 & 682 \\
08:00 (UTC+8), 20 Jul & 0.4826 & 683 \\
08:00 (UTC+8), 21 Jul & 0.5416 & 685 \\
08:00 (UTC+8), 22 Jul & 0.5263 & 181 \\
\hline
\end{tabular}

tion prospects in forecasting of regional large-scale fog-haze weather in North China.

\subsubsection{The 12 March 2014 clear-weather case analysis}

In order to investigate the analysis and identification capability of PLAM/h with regard to the clear and sunny weather without fog or haze, the correlation between PLAM/h and visibility in a wide range of clear weather has been determined. As an example, Fig. 8a and b show the correlation analysis of the regional PLAM/h distribution and PLAM/h index $24 \mathrm{~h}$ forecasts on 12 March 2014.

It is seen from Fig. 8a that most of North China has values of PLAM/h $<60$ (blue area in the figure). The meteorological conditions PLAM/h index distribution shows that a large part of North China lies in the area with meteorological conditions extremely favourable for atmospheric dispersion. Beijing at this time experiences blue sky with clouds. The PLAM/h index forecasts of Beijing and Baoding (Hebei) are 53 and 29, respectively. From daytime to evening on 
12 March, the $\mathrm{PM}_{2.5}$ value of the Beijing urban area is reported to be $21-35 \mu \mathrm{g} \mathrm{m}^{-3}$.

Figure $8 \mathrm{~b}$ shows the correlation analysis of PLAM/h index $24 \mathrm{~h}$ forecasts and observed visibility at 677 stations in North China on 12 March 2014, which was made based on real-time data. It can be seen that the determination coefficient $\left(R^{2}\right)$ reaches 0.412 and the significance level exceeds 0.001 on average. On 13 March 2014, Beijing continues to experience clear weather with blue sky and clouds, and so air quality is excellent. The $\mathrm{PM}_{2.5}$ value of the Beijing urban area still remains at high levels of $22-37 \mu \mathrm{g} \mathrm{m}^{-3}$. The above analysis indicates that, for large-scale clear weather or low-visibility heavy pollution weather, the PLAM/h index has strong identification, analysis, and forecasting capabilities.

\section{Conclusions}

PLAM - a meteorological pollution index for air quality has been developed and used in NRT air quality forecasts by considering both meteorology and pollutant emissions. Based on the emission-diagnosing model of two-dimensional probability density function, the paper has extended the parameterized description of original PLAM, applying it in the diagnosis and forecasting of the variation in and distribution of wide-range regional low-visibility fog-haze intensity and achieving satisfactory results. The contrast analysis with or without the emission impact indicates that meteorological conditions and emission factors jointly play a role in expanding PLAM towards a high-value zone. This means that the $\mathrm{PLAM} / \mathrm{h}$ index involving emissions has a significant effect on improving the capability of diagnosing and forecasting heavy fog-haze weather in North China.

The variation in air quality meteorological conditions index PLAM/h is significantly correlated with the regional visibility observations in North China. The determination coefficients of winter, summer, spring, and autumn are 0.8557 , $0.8009,0.7617$, and 0.9552 , respectively, and their average significance level exceeds 0.001 .

The correlation analysis of index and visibility regional distributions indicates that the high-correlation zones lie in Jing-Jin-Ji (Beijing, Tianjin, Hebei), Bohai Bay, southern Hebei, and northern Hubei. This indicates that the PLAM/h index is indicative to the distributions of the North China weather system and the heavy fog occurrence region as well as the distribution of emission high value zones.

The analyses of typical high-pollution cases of spring, summer, autumn, and winter suggest that PLAM/h index regional distribution is related to the banding distribution features of weather-scale systems in different seasons. The weather-scale high-value PLAM/h areas correspond to the low-visibility areas, indicating the PLAM/h index has the capability to diagnose, identify, and forecast with regard to wide-range fog-haze areas and their seasonal differences in North China.

Although winter is different from summer, the PLAM $/ \mathrm{h}$ index $24 \mathrm{~h}$ forecasts and visibility observations from the weather stations of North China, including wide-range clear weather and low-visibility heavy pollution weather, all have high correlations. This indicates the PLAM/h index has good identification, analysis, and forecasting capabilities. These conclusions show that the PLAM/h index will have good practical application prospects in forecasting large-scale foghaze areas and their seasonal differences in North China.

Acknowledgements. This work was funded by the National Key Foundation Study Developing Program (2011CB403404, 2011CB403401), National Key Technology R \& D Program (grant no. 2014BAC16B01), the National Natural Science Foundation of China (grant nos. 41275167, 41275007), and the CMA Innovation Team for Haze-fog Monitoring and Forecasting.

Edited by: J. Brandt

\section{References}

Gong, S. L., Barrie, A., Blanchet, J. P., Salzen, K. N., Lohmann, U., Lesins, G., Spacek, L., Zhang, L. M., Girard, E., Lin, H., Leaitch, R., Leighton, H., Chylek, P., and Huang, P.: Canadian aerosol module: a size-segregated simulation of atmospheric aerosol processes for climate and air quality models 1 . Module development, J. Geophys. Res., 108, 4007-4015, 2003.

Honoré, C., Rouil, L., and Vautard, R.: Predictability of European air quality: Assessment of 3 years of operational forecasts and analyses by the PREV'AIR system, J. Geophys. Res., 113, 43024310, 2008.

Kassomenos, P., Papaloukas, C., Petrakis, M., and Karakitsios, S.: Assessment and prediction of short term hospital admissions: the case of Athens, Greece, Atmos. Environ., 42, 7078-7086, 2008.

Kuo, H. L.: Convective Weather in Conditionally Unstable Atmosphere, Tellus, 13, 441-459, 1961.

Kuo, H. L.: On Formation and Intensification of Tropical Cyclone through Latent Heat Release in Cumulus Convection, J. Atmos. Sci., 22, 40-23, 1965.

Kuo, H. L.: Further Studies on the Parameterization of the Influence of Cumulus Convection in Large-scale Flows, J. Atmos. Sci., 31, 1232-1240, 1974.

Li, Y., Wang, W., Wang, J. Z., Zhang, X. L., Lin, W. L., and Yang, Y. Q.: Impact of air pollution control measures and weather conditions on asthma during the 2008 Summer Olympic Games in Beijing, Int. J. Biometeorol., 55, 547-554, doi:10.1007/s00484010-0373-6, 2010.

McKeen, S.: Evaluation of several real-time $\mathrm{PM}_{2.5}$ forecast models using data collected during the ICARTT/NEAQS 2004 field study, J. Geophys. Res., 112, D10S20, doi:10.1029/2006JD007608, 2007.

Moran, M. D.: On particulate matter formation in the Mediterranean Region, in: Proceedings of the 30th NATO/SPS ITM on Air Pollution Modelling and Its Application, San Francisco, 2009. 
Neumann, C. J. and Mandal, G. S.: Analog forecasting methods of tropical cyclones in India ocean, Indian J. Met. Geophys., 29, 487-500, 1978.

Rigby, M. and Toumi, R.: London air pollution climatology: indirect evidence for urban boundary layer height and wind speed enhancement, Atmos. Environ., 42, 4932-4947, 2008.

Wang, J. L. and Liu, X. L.: The Discuss on relationship between visibility and mass concentration of $\mathrm{PM}_{2.5}$ in Beijing, Acta Meteorl. Sin., 64, 221-228, 2006.

Wang, J. Z. and Neumann, C. J.: A Markov-type analogmedel for prediction of typhoon motion in Northwestern Pacific, Scientia Sin. B, 28, 517-526, 1985.

Wang, J. Z., Xu, X. D., and Yang, Y. Q.: A studyof characteristics of urban visibility and fog in Beijing and the surrouding area, J. Appl. Meteorol. Sci., 13, 160-168, 2002.

Wang, J. Z., Yang, Y. Q., Zhang, G. Z., and Yu, S. Q.: Climatic trend of cloud amount related to the aerosol characteristics in Beijing during 1950-2005, Acta Meteorol. Sin., 24, 762-775, 2010.

Wang, J. Z., Gong, S. L., Zhang, X. Y., Yang, Y. Q., Hou, Q., Zhou, C. H., and Wang, Y. Q.: A parameterized method for airquality diagnosis and its applications, Adv. Meteorol., 238589, doi:10.1155/2012/238589, 2012.
Wang, J. Z., Wang, Y. Q., Liu, H., Yang, Y. Q., Zhang, X. Y., Li, Y., Zhang, Y. M., and Deng, G.: Diagnostic identification of the impact of meteorological conditions on $\mathrm{PM}_{2.5}$ concentrations in Beijing, Atmos. Environ., 81, 158-165, 2013.

Yang, Y. Q., Wang, J. Z., Hou, Q., and Wang, Y. Q.: A Plam Index for Beijing Stabilized Weather Forecast in Summer Over Beijing, J. Appl. Meteorol. Sci., 20, 649-655, 2009.

Zhang, X. Y., Wang, Y. Q., Lin, W. L., Zhang, Y. M., Zhang, X. C., Gong, S. L., Zhao, P., Yang, Y. Q., Wang, J. Z., Zhou, Q., Zhang, X. L., Che, H. Z., Guo, J. P., and Li, Y.: Changes of atmospheric composition and optical properties over Beijing 2008 Olympic Monitoring Campaign, B. Am. Meteorol. Soc., 90, 1633-1649, 2009.

Zhang, X. Y., Sun, J. Y., Wang, Y. Q., Li, W. J., Zhang, Q., Wang, W. Z., Qian, J. N., Cao, G. L., Wang, J. Z., Yang, Y. Q., and Zhang, Y. M.: Factors contributing to haze and fog in China, Chinese Sci. Bull., 58, 1178-1187, doi:10.1360/972013-150, 2013. 